\title{
Management for Medically Unexplained Symptoms (MUS) in Primary Care Medicine
}

\section{Hiroshi Bando*}

Department of Medical Research, Tokushima University, Tokushima, Japan

Keywords: Primary care; Medically unexplained symptoms; Functional somatic symptoms; Somatic symptom disorders; Hinoharaism

Abbreviations: PC: Primary Care; MUS: Medically Unexplained Symptoms; FSS: Functional Somatic Symptoms; SSD: Somatic Symptom Disorders

Primary Care (PC), General Practice (GP) and Family Medicine (FM) have been important medical fields and developed for long years. PC has been introduced to Japan by Dr. Shigeaki Hinohara who was eminent physician worldwide lived until 105 years old [1]. He has been called as 'The Father of PC in Japan' and respected by medical staffs and people for his supreme Hinohara-ism. He has emphasized the importance of psychosomatic care in PC and also 'the balance of mind and body'.

As one of the disciples of Dr. Hinohara, the author participated in family practice residency program in United States and developed PC in Japan until now. In May 2017, I was the chairman of $8^{\text {th }}$ annual Congress of Japanese Primary Care Association (JPCA) and Dr. Hinohara gave us his last official message in his life concerning the development history of PC in Japan.

According to his advice, several medical associations have been established in Japan. Among them, main medical related societies are JPCA, Japanese Society of Psychosomatic Medicine (JSPM) and Japanese Society of Psychosomatic Internal Medicine (JSPIM). In these three academies, the goals and directions are very close and the author has been one of the board members with the role of developing psychosomatic medicine in Japan.

General practitioners or family physicians (GPs) in PC/GP/FP are managing various health problems and usually confronted with Medically Unexplained Symptoms (MUS) and other unselected health care problems [2]. In general, these symptom are approximately $20 \%$ observed in primary care setting [3,4]. There are similar medical terms about MUS so far, including Functional Somatic Symptoms (FSS), Somatic Symptom Disorders (SSD), somatic symptom distress, bodily-distress syndrome and so on. Furthermore, some critique and controversy have been found because of the ambiguity and definition of these medical terms and concept [5-7].

Patients with MUS show a variety of symptoms that are not attributable to a specific diagnosis. Furthermore, they present various degree of diseased states from mild self-limiting symptoms to severe, disabling disorders [8,9]. Consequently, GPs have often faced management challenges, when trying to classify diseased patients and offer them adequate support and treatment [10].

Concerning the percentage of MUS, there are several reports. The average data would be $10 \%-15 \%$ of all GP consultations [11]. Clinical prevalence of FSS was investigated and the results showed that the percentage of revised diagnosis was $8.8 \%$ [12]. Moreover, FSS occurs in as many as $30 \%$ of patients in general medical practice, but it is infrequently a topic of formal instruction [13]. Many physicians feel uncomfortable with MUS and are unfamiliar with how to manage them.

As a result, it is not easy for GPs to accurately assess, diagnose and treat MUS patients. Furthermore, it is especially more difficult to explain the patients about "borderline of medical region" and "cannot explain the detail" and also to show its evidence.

However, GPs can usually receive and accept a variety of complaints which are constantly spreading and can think about it with the patients together. Therefore, GPs tend to show less interest in diagnosis and detail classification with MUS [14]. The reason for this is that classification of MUS into detailed diagnostic categories is not consistent with essential measure of medical practice or not beneficial for solving the ambiguous problems about MUS [15].

As mentioned above, it is questionable how much the diagnostic categories of MUS and application of MUS are useful in the clinical setting of PC/GM/FM. Generally speaking, even clinicians and researchers feel that the concept of MUS is unclear and vague. In addition, it seems to be away from the conventional standard way of thinking that the problems of mind and body are separate for diagnosis and treatment.

On the other hand, there has been a meaningful concept, a biopsychosocial model. It was prevalent and accepted in the area of PC/ GM/FM and often emphasized as useful management of MUS.

Consequently, ambiguity and controversy have been present in clinical application of MUS. In the primary setting, there is not enough time to communicate and discuss about various problems with the patients. According to lots of studies concerning MUS, the doctorpatient relationship has been often a source of frustration due to differing illness perceptions in each patient [11].

When GPs are practicing medicine in primary care setting, there is an easy-to-refer recommended axis. It is to take advantage of the symptoms that are frequently observed in MUS. In meta-analysis which examined 3387 cases from 30 research reports, eight typical symptoms were investigated [16,17]. They are mixed chronic pain, chronic low back pain, fibromyalgia/chronic widespread pain, mixed/ tension headache, chronic fatigue syndrome, irritable bowel syndrome, interstitial cystitis and tinnitus.

Furthermore, it would be useful to utilize some factors in contact with our daily lives. From 47 research of somatoform disorders, four outcome domains were investigated. They are physical symptoms, health-related quality of life, depression and anxiety [18]. The results were that reduction in physical symptoms was correlated with reductions in depression and anxiety and increase in quality of life.

*Corresponding author: Hiroshi Bando, MD, PhD, FACP, Department of Medical Research, Tokushima University, Tokushima, Japan, Tel: +81-90-3187-2485; E-mail: pianomed@bronze.ocn.ne.jp

Received: August 21, 2018; Accepted: September 23, 2018; Published: September 30, 2018

Citation: Bando H (2018) Management for Medically Unexplained Symptoms (MUS) in Primary Care Medicine. Prim Health Care 8: 307. doi: 10.4172/2167. 1079.1000307

Copyright: (ㄷ 2018 Bando $\mathrm{H}$. This is an open-access article distributed under the terms of the Creative Commons Attribution License, which permits unrestricted use, distribution, and reproduction in any medium, provided the original author and source are credited. 
Research for MUS would be explored in not only medical practice, but also dental practice. Many dental patients complain of oral symptoms after treatment, including chronic pain, occlusal discomfort which cause remains undetermined. There are medically unexplained oral symptoms/syndromes such as atypical odontalgia, burning mouth syndrome, phantom bite syndrome, oral cenesthopathy and halitophobia [19].

There are challenges in coding of MUS and somatoform disorders. However, GPs probably tend not to utilize coding procedure, but to receive complaints and suffering of the patients and manage to respond uncertainty for the satisfaction of the patients [20]. Medical administration department has system for International Classification of Diseases $10^{\text {th }}$ Revision (ICD-10)-coding, but GPs and patients do not think it necessary requirement. Recent developments of Diagnostic and Statistical Manual of Mental Disorders (DSM-5) and the upcoming International Classification of Diseases $11^{\text {th }}$ Revision (ICD-11) may change the doctor-patient relationship in the future.

In summary, the understanding and management of MUS are fundamentally crucial from the primary care point of view. However, in the primary setting, GPs can respond the patients adequately beyond coding or computerized procedure. GPs can give them better body and mind relationship and happiness from the reliability and experience for years.

\section{References}

1. Bando H, Yoshioka A, Iwashimizu Y, Iwashita M, Doba N (2017) Development of primary care, lifestyle disease and new elderly association (NEA) in Japancommon philosophy with Hinohara-ism. Prim Health Care 7: 281.

2. Rosendal M, Carlsen AH, Rask MT, Moth G (2015) Symptoms as the main problem in primary care: A cross-sectional study of frequency and characteristics. Scand J Prim Health Care 33: 91-99.

3. Tschudi-Madsen H, Kjeldsberg M, Natvig B, Ihlebaek C, Straand J, et al. (2014) Medically unexplained conditions considered by patients in general practice. Fam Pract 31: 156-163.

4. den Boeft M, van der Wouden JC, Rydell-Lexmond TR, de Wit NJ, van der Horst HE, et al. (2014) Identifying patients with medically unexplained physical symptoms in electronic medical records in primary care: A validation study. BMC Fam Pract. 15: 1-109.

5. Creed F, Guthrie E, Fink P, Henningsen P, Rief W, et al. (2010) Is there a better term than "medically unexplained symptoms"? J Psychosom Res 68: 5-8.
6. Kroenke K, Sharpe M, Sykes R (2007) Revising the classification of somatoform disorders: Key questions and preliminary recommendations. Psychosomatics 48: $277-285$

7. Marks EM, Hunter MS (2015) Medically Unexplained Symptoms: An acceptable term? Br J Pain 9: 109-114.

8. Katon W, Lin E, Von Korff M, Russo J, Lipscomb P, et al. (1991) Somatization: A spectrum of severity. Am J Psychiatry 148: 34-40.

9. Rosendal M, Fink P, Falkoe E, Hansen HS, Olesen F (2007) Improving the classification of medically unexplained symptoms in primary care. Eur $\mathrm{J}$ Psychiat 21: 25-36.

10. Johansen ML, Risor MB (2017) What is the problem with medically unexplained symptoms for GPs? A meta-synthesis of qualitative studies. Patient Educ Couns 100: 647-654.

11. Brown RJ (2007) Introduction to the special issue on medically unexplained symptoms: Background and future directions. Clin Psychol Rev 27: 769-780.

12. Eikelboom EM, Tak LM, Roest AM, Rosmalen JGM (2016) A systematic review and meta-analysis of the percentage of revised diagnoses in functional somatic symptoms. J Psychosom Res 88: 60-67.

13. Graver CJ (2017) Functional somatic syndrome: Assessment and management. J Am Osteopath Assoc 117: 511-519.

14. Rask MT, Andersen RS, Bro T, Fink P, Rosendal M (2014) Towards a clinically useful diagnosis for mild-to-moderate conditions of medically unexplained symptoms in general practice: A mixed methods study. BMC Fam Pract 15: 118

15. Soler JK, Okkes I (2012) Reasons for encounter and symptom diagnoses: A superior description of patients' problems in contrast to medically unexplained symptoms (MUS). Fam Pract 29: 272-282.

16. Engel GL (1977) The need for a new medical model: A challenge for biomedicine. Science 196: 129-136.

17. Vugts MAP, Joosen MCW, van der Geer JE, Zedlitz AMEE, Vrijhoef HJM (2018) The effectiveness of various computer-based interventions for patients with chronic pain or functional somatic syndromes: A systematic review and metaanalysis. PLoS One 13: e0196467.

18. Chowdhury S, Burton C (2017) Associations of treatment effects between follow-up times and between outcome domains in interventions for somatoform disorders: Review of three cochrane reviews. J Psychosom Res 98: 10-18.

19. Toyofuku A (2016) Psychosomatic problems in dentistry. Biopsychosoc Med 10: 14.

20. Pohontsch NJ, Zimmermann T, Jonas C, Lehmann M, Löwe B, et al. (2018) Coding of medically unexplained symptoms and somatoform disorders by general practitioners-an exploratory focus group study. BMC Fam Pract 19 129 